\title{
Feasibility and Durability of Interlocks (Paving stones) from Polyethylene Terephthalate (PET) Wastes
}

\author{
Omosebi Taiwo O, Noor Faisal Abas
}

\begin{abstract}
Managing plastics waste is a global challenge that challenges the health of our ecosystem due to their high rate of production and non-biodegradability. However, it is important to handle PWs properly to curtail the environmental emissions associated with their incineration and dumping into landfills. The world's building industry is influenced by looking at the expense of construction materials and the required raw materials to manufacture them with the supporting climate that is rising at an unprecedented pace. The recycling of plastic waste into new useful building construction products will be a great advantage In this analysis, the shredded PET waste gathered from the recycling center was heated to $230{ }^{\circ} \mathrm{C}$ and used as a binder for the complete substitution of cement with a river sand aggregate for the manufacture of polymer interlocking / paving stones. The physical characteristics and mechanical performance of the aggregate materials and PET polymer concrete (including their distribution of particle size, silt, clay and dust content, relative stiffness, water absorption, porosity, flexural and compressive strength) were tested on various PET waste: $100 \%, 90 \%, 70 \%$, $50 \%$ and $30 \%$ sand mixing percentages. The results showed that the produced interlocks from $30 \%$ PET and $70 \%$ river sand (3:7) achieved higher density, flexural, and compressive strength than the other combination percentages. The least strength and porosity were exhibited by the polymer concrete produced with $100 \%$ PET. The compressive strength of the PET polymer concrete produced with $30 \%$ PET waste composition was higher than that of cement concrete at 28 days curing. Based on the test results, PET polymer concrete at $30 \%$ PET replacement can be used for interlocking tiles / paving stones due to its strength, low water absorption, and eco-friendliness, especially in water-logged areas. This prospect of interlocking tile production using polyethylene terephthalate (PET) waste and sand would not only minimise the cost of building production, but will only act as a waste diversion to mitigate environmental emissions caused by plastic waste disposal.
\end{abstract}

Keywords: Paving stones; Plastic wastes; Pollution; Interlocks; Aggregates; Recycling; Polymer concrete.

\section{INTRODUCTION}

Plastic is a synthetic, solid, hydrocarbon-based polymer; it can either be a thermoplastic or thermosetting material. Thermoplastic is a plastic material that can soften upon heating and harden when cooled; hence, it can be molded into different shapes. Thermosetting materials cannot be remelted when they solidify; they are mainly used as Bakelite [1]. Plastics are in common use due to their lightweight, soft nature, flexibility, non-corrosiveness, and durability.

Revised Manuscript Received on September 25, 2020.

* Correspondence Author

Omosebi Taiwo O*, School of Housing, Building and Planning, University Sains Malaysia

Noor Faisal Abas, School of Housing, Building and Planning, University Sains Malaysia

(c) The Authors. Published by Blue Eyes Intelligence Engineering and Sciences Publication (BEIESP). This is an open access article under the CC BY-NC-ND license (http://creativecommons.org/licenses/by-nc-nd/4.0/)
Plastics are comfortable packing materials and containers but wastes from plastics are a major cause of environmental pollution; they emit poisonous gases upon incineration and are not biodegradable. Plastic materials are reportedly carcinogenic as they contain chlorine and other carcinogens. Burning of plastic wastes produces toxic gases such as phosgene, carbon monoxide, chlorine, sulfur dioxide, nitrogen oxide, and other deadly dioxins that are harmful to the environment. Since plastic wastes account for the highest percentage of waste produced globally, there is a need to ensure proper management of such waste. Plastics are commonly used as packing materials, but their wastes can be used in the construction industries to produce construction materials, such as floor tiles, roof tiles, building blocks, etc. This can reduce construction costs and minimize environmental pollution. For instance, plastic wastes can be mixed with sand and other additives to produce constructional materials [5]. Presently, recycled plastic wastes are gradually replacing natural materials such as fiber, metal, wood/timber, and sand, thereby preserving the natural environment. Proper management of solid wastes through recycling into new products will help to promote a sustainable environment, conservation of natural resources, and cheap raw materials [4]. On the other hand, the lack of adequate management of solid wastes will add to the existing environmental problem; hence, solid wastes must be properly managed by recycling them into new useful products $[3,5]$. Being that plastic wastes cannot decompose easily and are produced in huge quantities, their deposition into landfills may not be a permanent solution [13]. Recycling is currently not an easy management strategy for plastic materials because it is a labor and capital-intensive process [9]. Previously, plastics were considered environmentally friendly materials that save energy, reduces raw material extraction, and fight climate change. However, the rate of plastic wastes generation has increased tremendously, and management has become a serious issue. Consequently, researchers have suggested the use of plastic wastes in concrete production for two major reasons: (i) to resolve the environmental problem associated with their disposal; and (ii) to reduce construction costs since they are available in great quantities [9]. Cement is generally used as a binder in the construction industry; however, the high cost of cement has prevented many people from building their houses and has hindered the advancement of the construction sector [15] [16]. Hence, it is important to find a suitable replacement for this expensive and essential building material $[17,18]$.

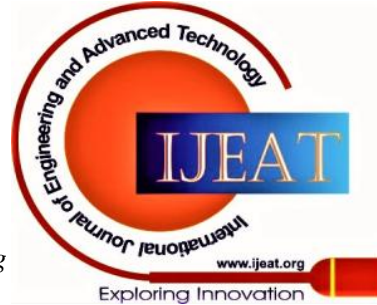


This study aims to examine the viability of utilizing PET wastes as a binder in full replacement of cement to produce interlocks / paving stones. The main objectives of this study are to evaluate the possibility of recycling PET wastes to produce interlock tiles, as well as to examine the physical and mechanical performance of the PET polymer concrete as interlocks.

\section{MATERIALS \& METHODS}

\subsection{Materials used to make the pavement stones}

The materials used in making the pavement stones were sourced locally; the locally sourced materials include plastic wastes, sand, metal mold, wood stirrer, sieve, hand gloves, coal pot, nose mask, and engine oil.

\subsubsection{Production of the paving stones}

The following steps were followed to produce the paving stones:

i) Procurement of PET wastes and sand

The PET wastes used in this study were shredded plastic water bottles collected from a Waste Resource Management Company located at 14000 Bukit Mertajam, Penang, Malaysia. The river sand used was supplied to the School of Housing, Building, and Planning Resource Laboratory. Figs. $1 \& 2$ showed the bags of shredded PET wastes and the river sand sample, respectively.
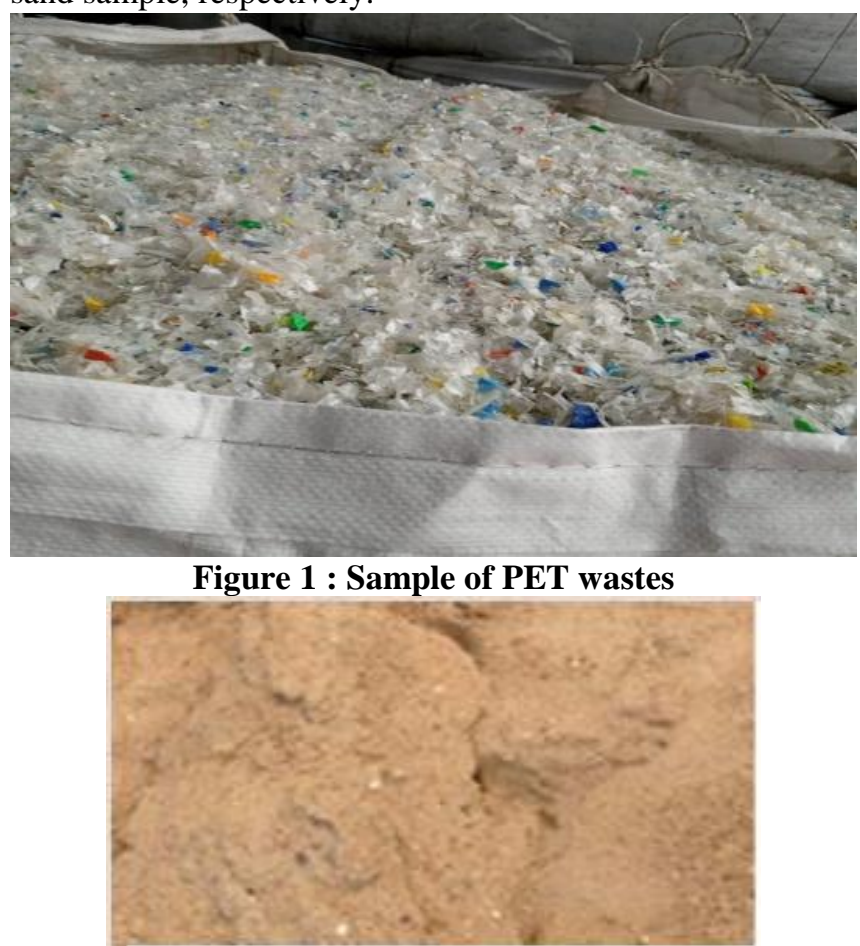

Figure 2. Sample of River Sand
The shredded PET wastes were heated and melted inside the aluminum pot at a temperature of $230^{\circ} \mathrm{C}$ before adding the fine river sand into the melted plastic wastes at different percentages. The mixture was homogenized and poured into a 5-cm thick iron mold that has been lubricated with engine oil for easy removal. The edge of the mold was banged continuously for proper compassion. After one hour, the samples were de-molded, cooled, and cured under ambient temperature for forty-eight hours before testing (see Fig. 3 \& 4).

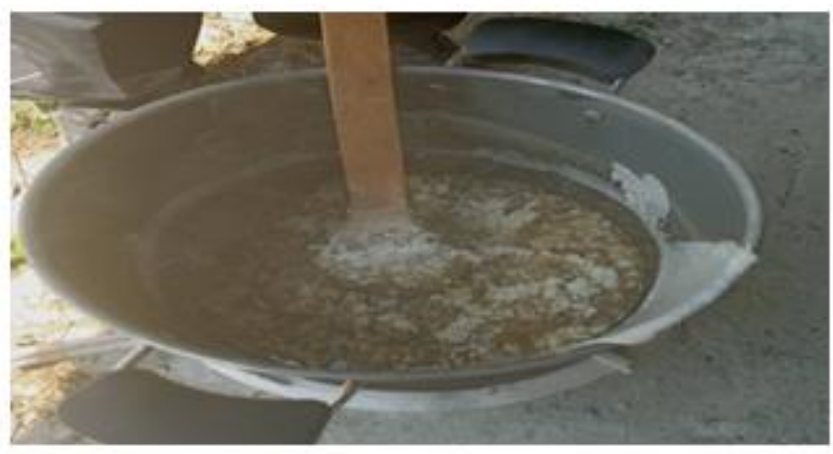

Figure 3. Mixing of melted wastes with sand

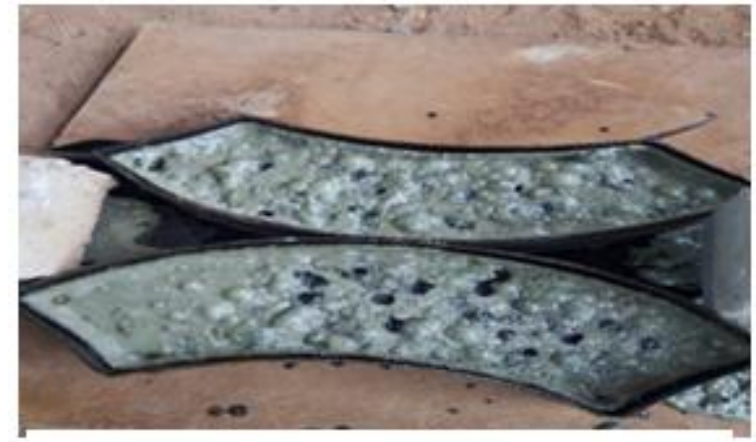

Figure 4. Sample of the produced plastic tiles/ interlocks

\section{RESULTS \& DISCUSSION}

\subsection{Sand Sieve analysis}

The aim of the sieve analysis test is to determine the grades of the sand aggregates. The test result (shown in Table 1 \& Fig. 5) showed that the sand sample was properly graded. The obtained coefficient of uniformity (0.2), coefficient of gradation (0.6), and fineness modulus (1.93) values supported the suitability of the aggregate for construction purposes as per the ASTM C33 standard.

Table 1. Particle size distribution of the sand; Dry sample weight $=\mathbf{5 0 0} \mathbf{g}$

\begin{tabular}{|l|l|l|l|l|}
\hline Sieve number & Diameter $(\mathrm{mm})$ & Soil retained $(\mathrm{g})$ & Soil retained (\%) & Soil passing (\%) \\
\hline $5.00 \mathrm{~mm}$ & 5 & 0.00 & 0.00 & 100.0 \\
\hline $2.36 \mathrm{~mm}$ & 2.36 & 1.00 & 0.20 & 99.8 \\
\hline $1.18 \mathrm{~mm}$ & 1.18 & 23.00 & 4.70 & 95.1 \\
\hline $600 \mu \mathrm{m}$ & 0.6 & 113.00 & 23.40 & 71.7 \\
\hline
\end{tabular}




\begin{tabular}{|l|l|l|l|l|}
\hline $300 \mu \mathrm{m}$ & 0.3 & 191.00 & 39.60 & 32.1 \\
\hline $150 \mu \mathrm{m}$ & 0.15 & 114.00 & 23.60 & 8.5 \\
\hline Pan & & 41.00 & 8.50 & 0.0 \\
\hline & TOTAL: & 483.00 & & \\
\hline
\end{tabular}

Fineness Modulus $=1.93$

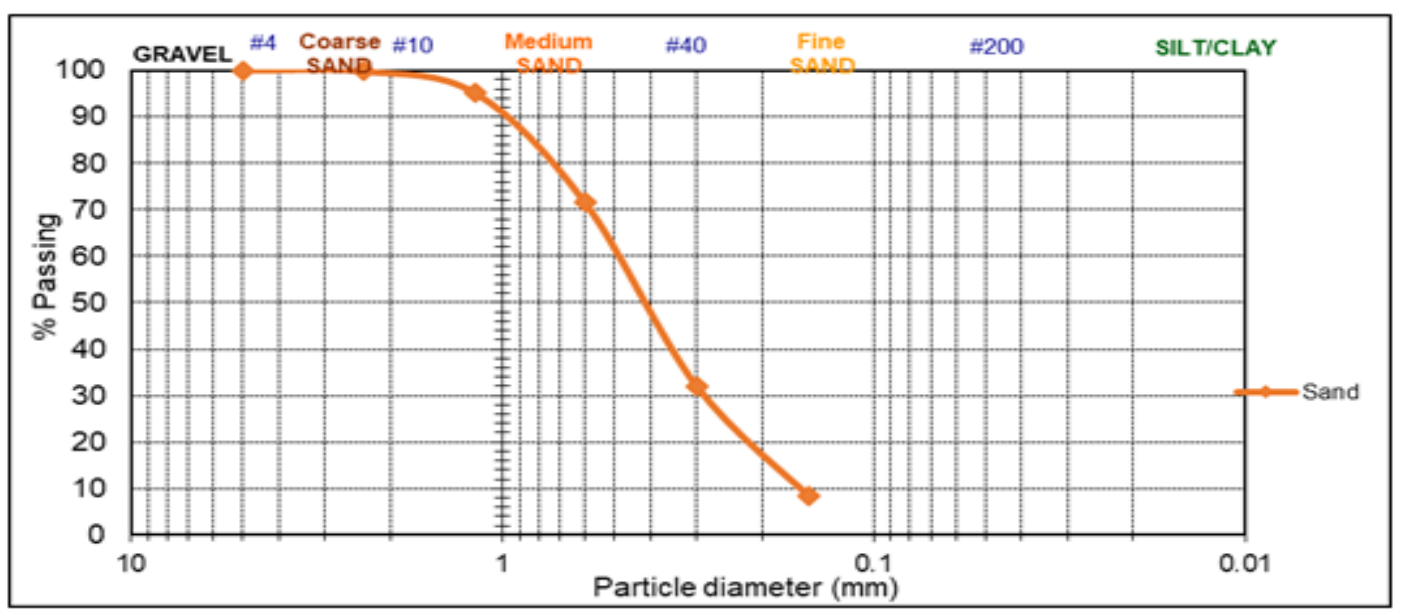

Figure 2 : Particle size distribution of river sand

3.2. Relative Density and Water Absorption of Sand Aggregates.

About $500 \mathrm{~g}$ of the sand sample was soaked in water for 24 hours to determine the relative density and water absorption capacity of the sand. The initial weight of the soaked sand was noted before sun-drying the sand and re-weighing at surface dried. The sand was further dried for 24 hours before measuring the average relative density and water absorption capacity. The results showed that the sample had an average relative capacity of 2.38 and a water absorption percentage of $0.07 \%$ (Table 2 ). The result was within the specified range for fine aggregates by ASTM C128. The relative density of natural aggregates has been suggested to be within the range of 2.4 - 2.9 (Kosmatka et al., 2013).

Table 2: Relative density and water absorption of sand aggregate

\begin{tabular}{|l|l|l|l|l|l|l|l|}
\hline Test no & $\begin{array}{l}\text { A } \\
\text { (g) }\end{array}$ & $\begin{array}{l}\text { B } \\
\text { (g) }\end{array}$ & $\begin{array}{l}\text { C } \\
\text { (g) }\end{array}$ & $\begin{array}{l}\text { D } \\
\text { (g) }\end{array}$ & $\begin{array}{l}\text { Relative density } \\
\text { (Oven-dried } \\
\text { basis) } \\
\left(\frac{\mathbf{D}}{(\mathbf{A}-(\mathbf{B}-\mathbf{C})}\right)\end{array}$ & $\begin{array}{l}\text { Relative density } \\
\text { (Saturated } \\
\text { surface dried) } \\
\left(\frac{\mathbf{A}}{\mathbf{A}-(\mathbf{B}-\mathbf{C})}\right)\end{array}$ & $\begin{array}{l}\text { Water absorption } \\
\text { \% of dry mass }\end{array}$ \\
$\left(\frac{\mathbf{1 0 0}(\boldsymbol{A}-\boldsymbol{D})}{\mathbf{D}}\right)$ \\
\hline 1 & 471 & 1,801 & 1,540 & 471 & 2.24 & 2.24 & 0 \\
\hline 3 & 498 & $1,819.3$ & $1,508.1$ & 497 & 2.66 & 2.67 & 0.20 \\
\hline Average & 497 & $1,822.2$ & $1,506.6$ & 497 & 2.74 & 2.24 & 0 \\
\hline
\end{tabular}

$\mathrm{A}=$ mass of the saturated surface dry sample in air; B =mass of the cylinder + sample + water; $\mathrm{C}=$ mass of the Cylinder + water; $\mathrm{D}=$ mass of the oven-dried sample in air.

\subsection{Clay, Silt and Dust Content}

The soil sample (500 g) was dried for 24hrs and washed thoroughly with water before sieving with a 75-um sieve and weighing. The soil sample was oven-dried again for 24 hours and re-weighed before the percentage silt, clay, and dust content was calculated as follows:

Pre-washing sample dried weight $(\mathrm{A})=487 \mathrm{~g}$

Post-washing sample dried weight $(\mathrm{B})=478 \mathrm{~g}$
Silt, clay \& dust content $(\%)=\left(\frac{A-B}{B}\right) \times 100$

$=(487-478 / 478) \times 100$

$=(9 / 478) \times 100$

$=1.88 \%$

3.4 PET Wastes Sieve Analysis

Sieve analysis was also conducted on the PET waste aggregates to determine the gradation. The result (Table 3 and Fig. 6) showed that the Fineness Modulus of the aggregates was 2.75 which suggest a proper gradation of the aggregates for construction purposes as per ASTM C33 standards.

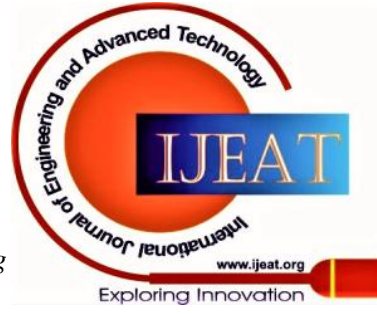


Feasibility and Durability of Interlocks (Paving stones) from Polyethylene Terephthalate (PET) Wastes

Table 3. PET wastes particle size distribution; weight of dry sample $=500 \mathrm{~g}$

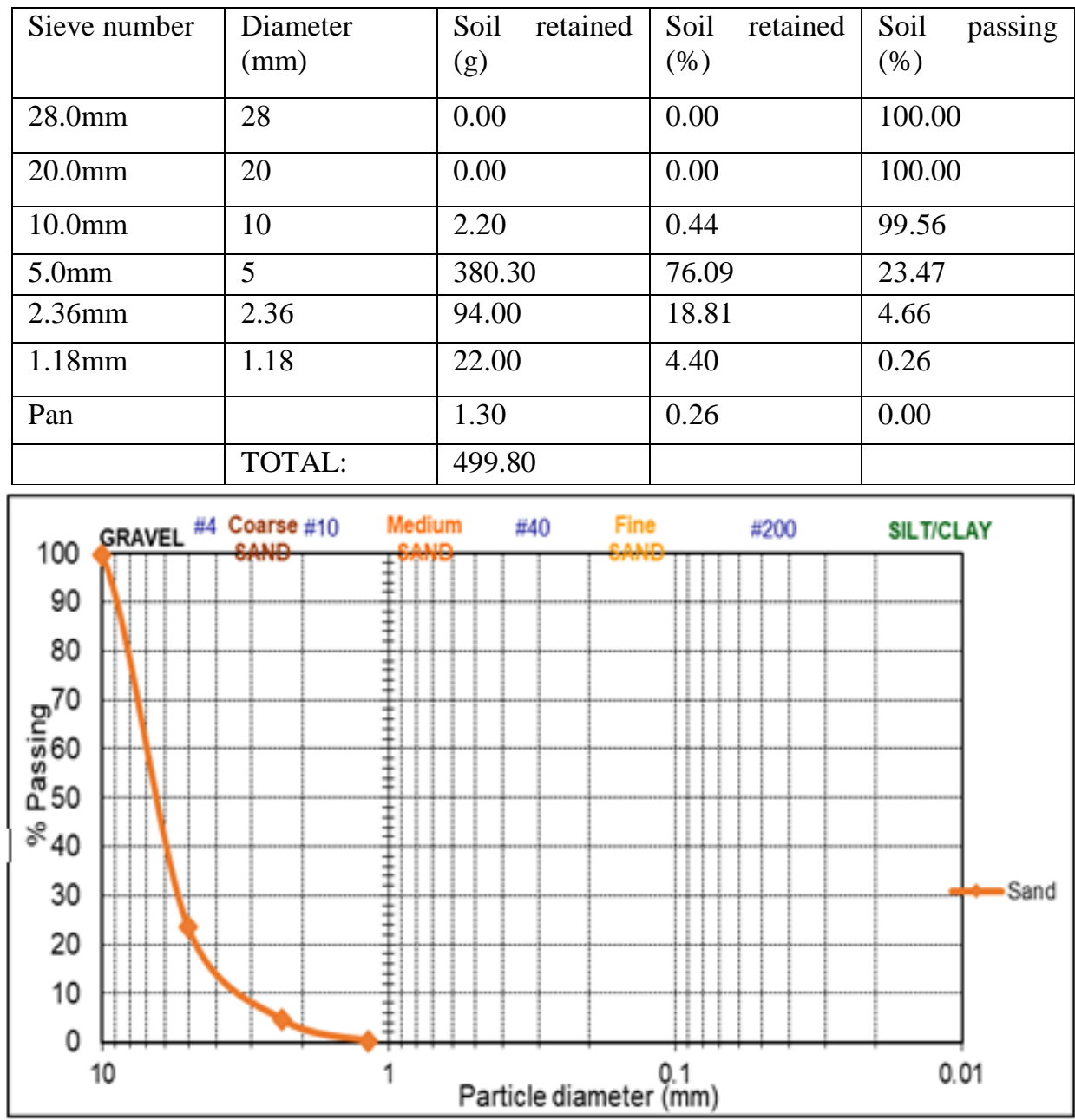

Figure 6. Particle Size distribution of PET wastes

3.5 Density of the PET polymer concrete

The density of the PET polymer concrete was determined, and the result showed that

the produced PET composite with $100 \%$ PET had the lowest density $\left(1,070.13 \mathrm{~kg} / \mathrm{m}^{3}\right)$ while those produced with $30 \%$ PET content had the highest density $\left(1,946.7 \mathrm{~kg} / \mathrm{m}^{3}\right)$ as shown in Fig. 7 . Observably, increases in the PET content decreased the density of the PET composite.

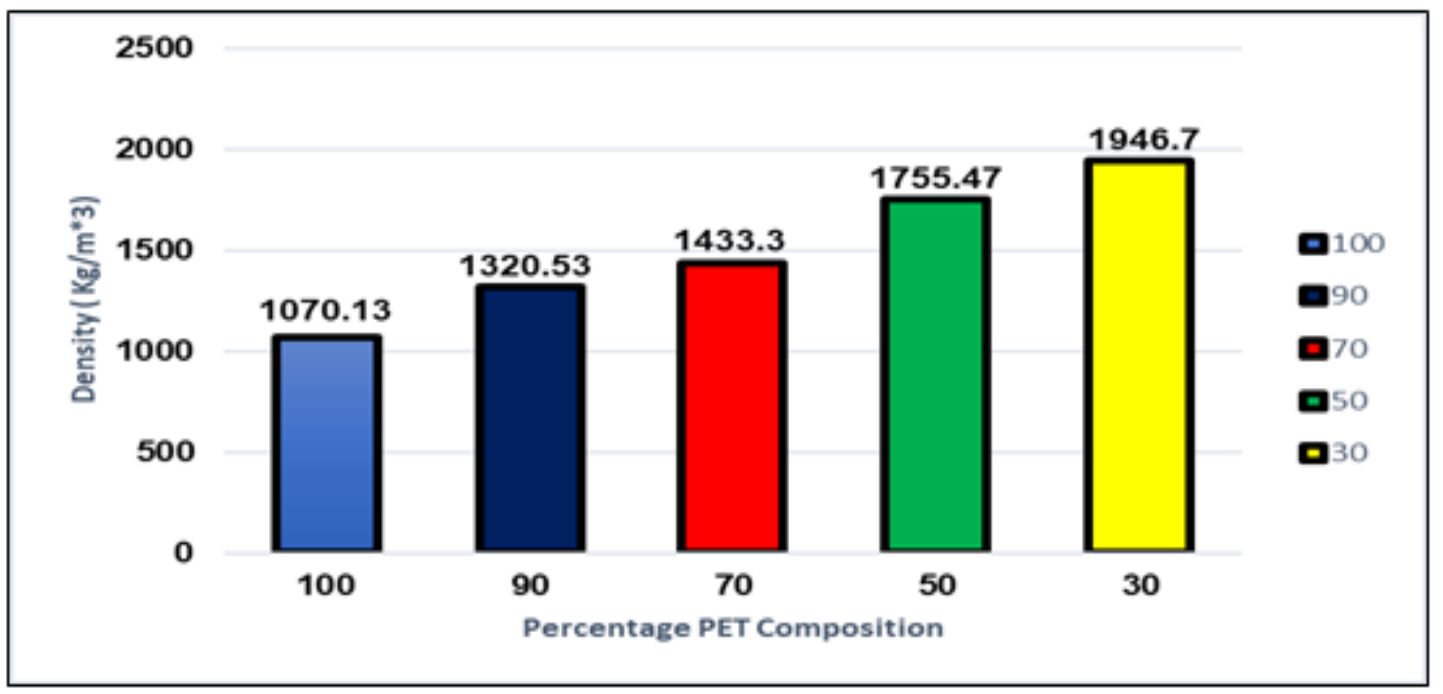

Figure 7. Average density of the samples

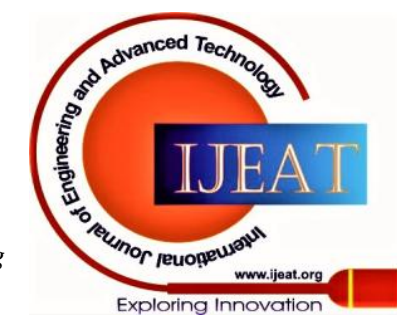




\subsection{Compressive Strength of PET composite}

PET composite that contain $100 \%$ PET exhibited the lowest compressive strength value $\left(0.012 \mathrm{~N} / \mathrm{mm}^{2}\right)$ while those produced with $30 \%$ PET content had the highest compressive strength value $\left(19.708 \mathrm{~N} / \mathrm{mm}^{2}\right)$ as shown in Fig. 8. The compressive strength value steadily increased with the sand content but decreased with increasing PET content. The observed compressive strength value in this study was significantly higher than the value for residential concrete at 28 days $\left(17 \mathrm{~N} / \mathrm{mm}^{2} ; \mathrm{p}<0.05\right)$. The ASTM C39 standard recommended a compressive strength of 2500 $\mathrm{psi} / 17.237 \mathrm{MPa} / 17.237 \mathrm{~N} / \mathrm{mm}^{2}$ for residential purposes.

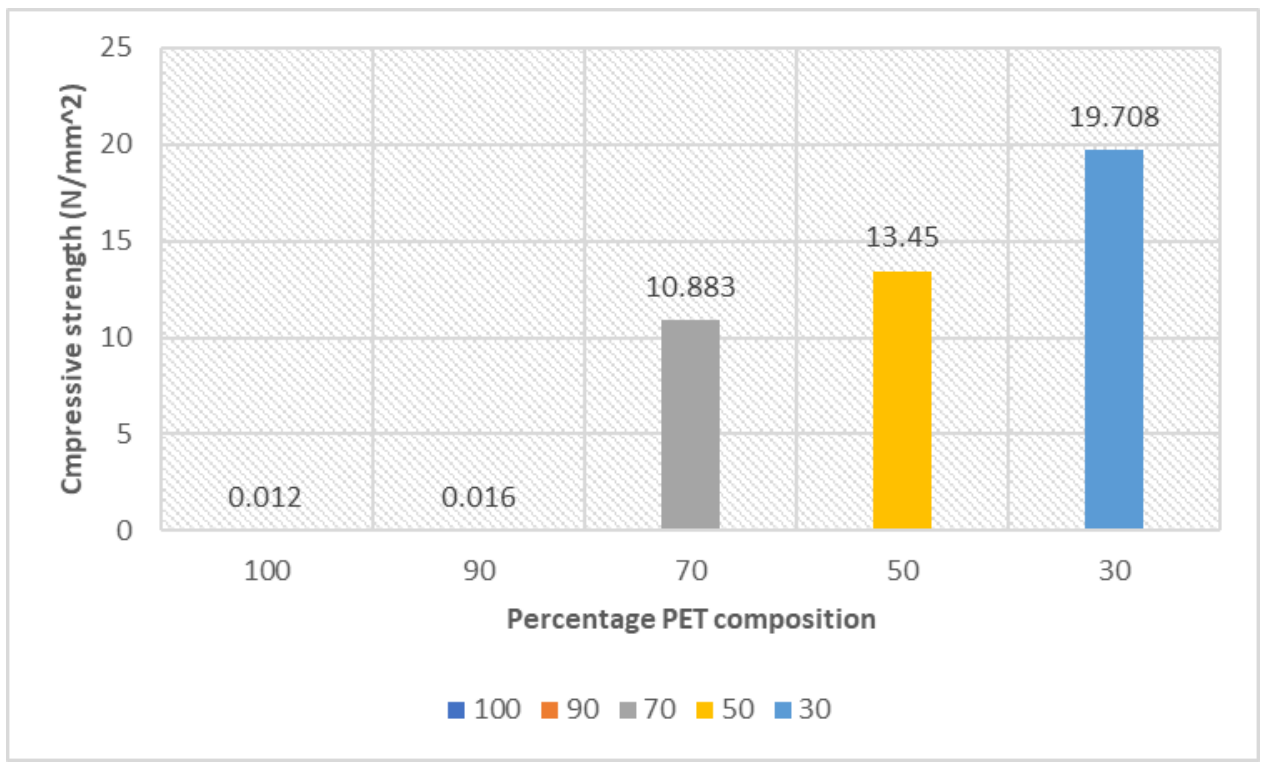

Figure 8. Average compressive strength values of the respective samples.

\subsection{Porosity of the PET polymer concrete}

The PET plastic composites produced with 50 \% PET content presented the highest porosity value of $2.97 \%$ while those containing $100 \%$ PET achieved the lowest porosity value of $1.35 \%$ (see Fig. 9). This implies that the porosity value of the PET polymer concrete decreases with increasing PET content.

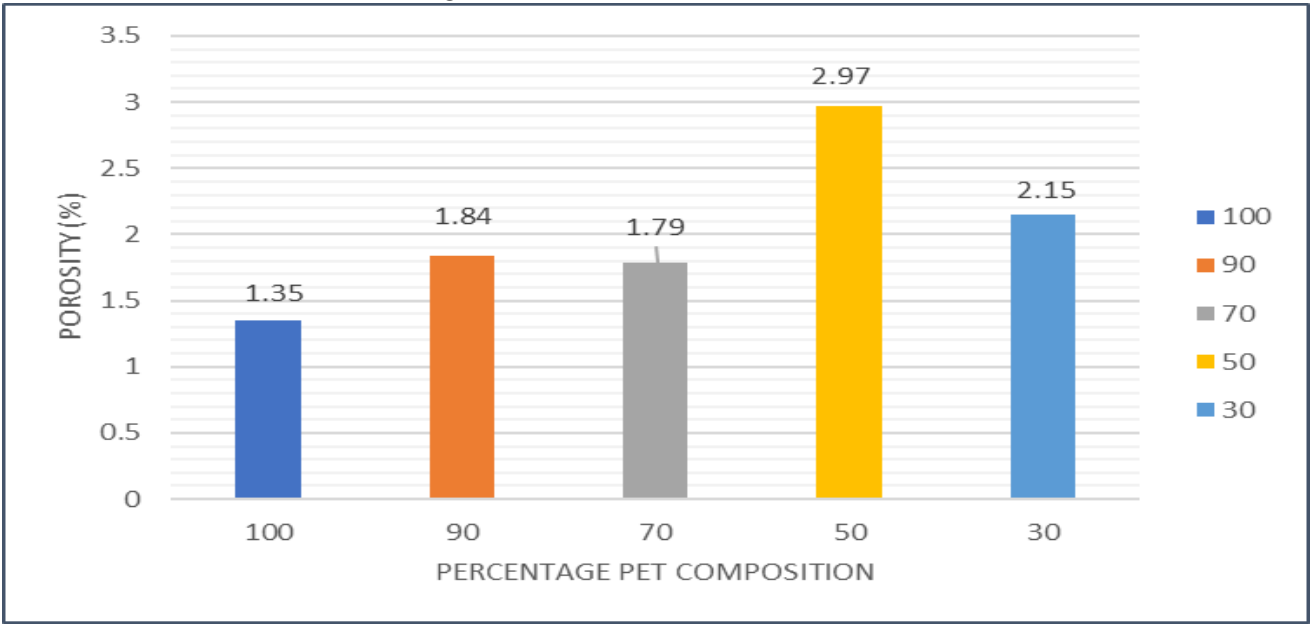

Figure 9. Porosity of the samples

\subsection{Flexural strength of the PET polymer concrete}

PET polymer concrete produced with $30 \%$ PET and $70 \%$ sand achieved the highest flexural strength value $\left(5.828 \mathrm{~N} / \mathrm{mm}^{2}\right)$ while those produced with (100\% PET) and (90\% PET + $10 \%$ sand) presented the lowest values (see Fig 10). This means that the flexural strength of the PET polymer concrete is directly a function of the sand content but inversely related to the PET content.

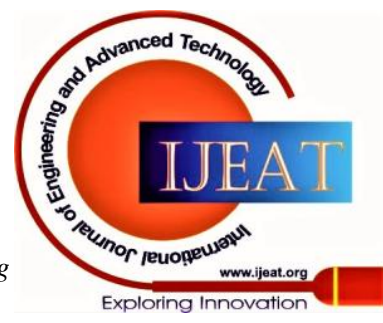




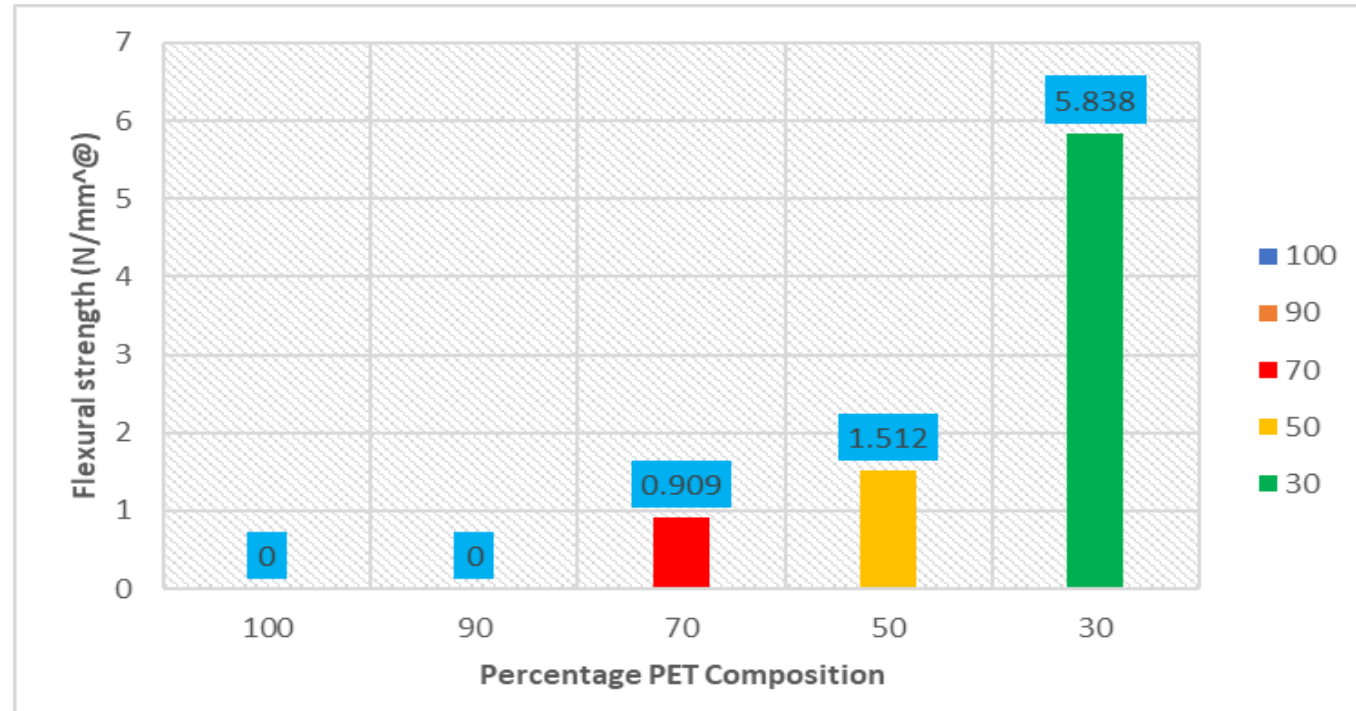

Figure 3 : Flexural strength of the samples

IV.

\section{CONCLUSION AND THE RESEARCH GAP}

Based on the outcome of the experiment carried out, the following conclusions can be drawn: The compressive strength and flexural strengthy of polymer concrete for plastic paving stones / interlocking tiles decreases with an increase in percentage of PET sand waste composition in the mixture, the compressive strength of polymer concrete for plastic paving tiles containing PET waste decreases from $19,708 \mathrm{~N} / \mathrm{mm}^{2}$ to $0,012 \mathrm{~N} / \mathrm{mm}^{2}$ and the flexural strength decreases from 5,838 $\mathrm{N} / \mathrm{mm}^{2}$ (30 per cent PET) to zero (100 per cent PET).The density of polymer concrete for plastic paving stones / interlocking tiles decreases with an increase in the proportion of PET content, the greater the volume of PET in the mixture, the lower the density. Decrease in density from $1946.7 \mathrm{~kg} / \mathrm{m}^{3}$ (containing 30\% PET composition) to $1070.13 \mathrm{~kg} / \mathrm{m}^{3}$ (containing $100 \%$ PET composition).

The porosity of polymer concrete for plastic interlocking tiles reduces as the volume of PET waste in the mixture has increased. That is, the higher the proportion of PET waste, the lower the amount of porosity. Porosity declined from 2.92 per cent to 1.35 per cent. Based on numerous research results, it has been demonstrated that plastic waste that is not biodegradable and takes several years to decompose, rendering it a threat to the atmosphere, can be recycled into construction materials as an alternative to lowering the cost of building materials and therefore saving the world. Analysis of the polymer concrete produced has shown that PET polymer concrete can be used as interlocking or paving stones. However, the test findings have shown that the required PET content for maximum output must not exceed 30 per cent PET +70 per cent sand because this mixture would create interlocks with a higher compressive strength than cement concrete after 28 days of curing. The density, flexicurity and water absorption ability of $30 \%$ PET concrete was also higher than that of the other percentages.

In conclusion, solid and eco-friendly interlocks can be created using 30\% PET waste and river sand, at which stage most of the materials are beyond the allowable limits. The interlocks produced are cheaper than standard tiles and can be used in many places especially in frost and water-logged environments. Due to the high cost of cement, which has stopped many people from constructing their houses and hindered the growth of the construction sector, as cement is usually used as a binder in the construction industry; it is therefore necessary to find a suitable replacement for this costly and critical building material by using PET waste as a substitute for this crucial material to manufacture new materials Furthermore, it is proposed that the government and the building regulator will come forward with legislation to promote the use of plastic interlocking tiles / paved stones manufactured from recycled PET waste.

\section{Declaration and Competing Interest}

There is no conflict of interest between the authors

\section{AKNOWLEDGEMENT}

The authors would like to acknowledge the School of Housing Building and Planning, USM, Malaysia. For the financial support for the publication of this article. The editor and the anonymous reviewers are also appreciated for their valuable feedback during the review process.

\section{REFERENCES}

1. Semiha Akçaözoğlu, (2015) 'Evaluation of waste plastics as recycled plastic composite materials', Journal of Waste Management, Vol. 1, pp. 16-19. Edorium.

2. Abeer, S.A.R., El Nashar, D.E., Abd-El-Messieh, S.L., and K.N. Abd-El Nour K.N., (2009) "Master. Des"., 30, 3760

3. Siti Aishah Wahid, Sullyfaizura Mohd Rawi, Noelia Md Desa, (2015) 'Utilization of Plastic Bottle Waste in Sand Bricks', Journal of Basic and Applied Scientific Research, ISSN 2090-4304, Vol. 5(1), pp. 3544.

4. Sadiq, M.M., and Khattak, M.R. (1999) "An Overview of Plastic Waste Management', Journal of Emerging Technologies and Innovative Research (JETIR), 2(6), Plastic Waste Management Institutes, Central Pollution Control Board, Delhi.

5. Anslem E. O., Eneh, (2015) 'Application of Recycled Plastics and Its Components in the Built Environment', BEST: International Journal of Management, Information Technology and Engineering ISSN 2348-0513, Vol. 3, Issue 3, pp. 9-16, Delhi.

6. Rajesh C., Manoj, K.C., Unnikrishnan, G., and Purushothaman E. (2011) Adv. Polym. Technol., 32, S1

7. Dr. Pawan Sikka, 'Plastic Waste Management In India', Department of Science \& Technology, Government of India New Delhi, India, pp. $1-4$.

\section{Published By:}

Blue Eyes Intelligence Engineering and Sciences Publication

(C) Copyright: All rights reserved.

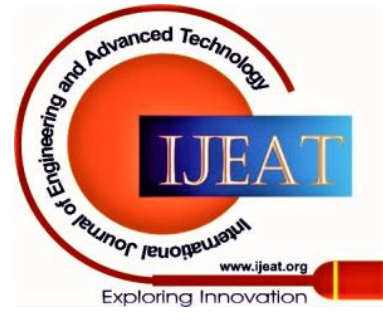


8. EPA 430-R-11-005. (2011) "Inventory of U.S. Greenhouse Gas Emissions and Sinks: (1990-2009)”, U.S. Environmental Protection Agency homepage. Available at: http://www. epa.gov. U.S.

9. Melik Bekhiti, Habib Trouzine, Aissa Asroun, (2014) 'Properties of Waste Tire Rubber Powder', Engineering, Technology \& Applied Science Research, Vol. 4, No. 4, pp. 669-672.

10. Noel Deepak Shiri, P. Varun Kajava, Ranjan H. V., Nikhil Lloyd Pais, Vikhyat M. Naik, (2015) "Processing of Waste Plastics into Building Materials Using a Plastic Extruder and Compression Testing of Plastic Bricks", in Journal mechanical Engineering and Automation, Vol.5(3B), pp. 39 - 42.

11. Patil, P.S Mali, J.R Tapkire, G.V., and Kumavat, H.R. (2015) "Innovative techniques of waste plastic used in concrete" in Journal mechanical Engineering and Automation, vol.5 pp 1800-1803.

12. Konin, A. (2011). "Use of plastic wastes as a binding material in the manufacture of tiles: the case of wastes with a basis of polypropylene”. In jourmal of Materials and structures RILEM, 13811387.

13. Otuoze H. S., Amartey Y. D., Sada B. H., Ahmed H. A., Sanni M. I. \& Suleiman M. A. (2012) "Characterization of sugar cane bagasse ash and Ordinary Portland Cement Blends in Concrete", in

14. 4th West African Built Environment Research (WABER) Conference (pp. 1231-1237). Abuja, Nigeria.

15. Ramaraj, A. P., \& Nagammal, A. N. (2014). "Exploring the current practices of post-consumer PET bottles and innovative applications as a sustainable building material" in 30th International Plea Conference (pp. 16-18). Ahmedabad: Cept University Press.

16. Velumani P., \& Karthik S. G., (2017). "Development of ecofriendly pressed roof tiles: A prologue study" in International journal of scientific and engineering s research, 8 (12), 20302033 xvii.

17. British Standard (BS EN ISO 62). (1999) "Plastics-determination of water absorption" in British Standard, United Kingdom.

18. American Society for Testing and Materials ASTM C33 (2003) "Standard Specification for Concrete Aggregate" in West Conshohocken, PA, USA.

19. CHOUGULE R.S., Magdum J.J., Jaysingpur Sayali Yanmar, Jaysingpur Sonam, Salunkhe, Jaysingpur Poonam PatilJaysingpur Akshay Saitawadekar, Jaysingpur Mandar Japanese, (2017)“USE OF PLASTIC WASTE IN CIVIL CONSTRUCTION" in International Journal of Engineering Technology, Management, and Applied Sciences www.ijetmas.com Volume 5 Issue 4, ISSN 2349-4476, Japan.

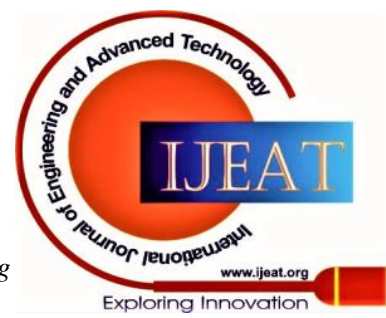

